Revista Española de Antropología Americana

ISSN: 0556-6533

https://dx.doi.org/10.5209/reaa.72826

\title{
Itinerarios historiográficos: otredades absolutas e imágenes disciplinares sobre Tierra del Fuego
}

\author{
Romina Casali ${ }^{1}$ y Alberto Harambour ${ }^{2}$
}

Recibido: 2 de diciembre de 2020 / Aceptado: 12 de enero 2021

Resumen. En este trabajo se enumeran las aproximaciones historiográficas sobre la Tierra del Fuego, teniendo en cuenta que, con foco en la consideración de las comunidades indígenas, no siempre son discernibles los límites disciplinares, y que se trata de un caso en donde la renovación profesional fue más bien tardía. Se plantea que la marginalidad espacial y el tipo de colonización de Patagonia Austral posicionaron a la Historiografía en un plano secundario respecto de otras disciplinas como la Antropología o la Arqueología; a su vez, la Isla Grande quedó relegada en los abordajes disciplinares incluso cuando éstos aludieron a "la Patagonia" como un bloque.

Palabras clave: Historiografía; comunidades fueguinas; extinción; genocidio.

\section{[en] Historiographic Itineraries: Absolute Otherness and Disciplinary Images on Tierra del Fuego}

\begin{abstract}
This article identifies a number of historiographical approaches on Tierra del Fuego, considering that the focus on indigenous communities does not allows to define clear disciplinary boundaries. At the same time, it argues that renewed gazes were expressed rather late when compared to other regions of Argentina and Chile. Spatial marginality and the peculiar type of colonization posited the historiographical discourses in a secondary position, regarding the continuity of anthropology and archaeology; at the same time, the Isla Grande was relegated even when Patagonia was studied as a whole, insular and continental
\end{abstract}

Keywords: historiography; fueguian communities; extinction; genocide.

Sumario: 1. Introducción. 2. La historiografía en segundo plano: fundamentación contextual. 3. Recorrido historiográfico sobre Tierra del Fuego. 4. A modo de cierre. 5. Referencias.

Cómo citar: Casali, Romina y Alberto Harambour. 2021. «Itinerarios historiográficos: otredades absolutas e imágenes disciplinares sobre Tierra del Fuego». Revista Española de Antropología Americana 51: 203-215.

\section{Introducción}

La historiografía es una construcción facto-intelectual formada por historias aprehendidas y reproducidas académicamente, con el inherente desafío de, en esos acon-

\footnotetext{
1 Consejo Nacional de Investigaciones Científicas y Técnicas (CONICET). Instituto de Humanidades y Ciencias Sociales (INHUS), Universidad Nacional de Mar del Plata, Argentina. romina.casali@gmail.com.

2 Universidad Austral de Chile; Centro IDEAL (FONDAP); IR Fondecyt 1181386, Chile. albertoharambour@ gmail.com.
} 
teceres, identificar la identidad e intencionalidad de los escribientes y las cualidades otorgadas a los objetos/sujetos de estudio. En esta línea, la narrativa historiográfica sobre Tierra del Fuego está sujeta por el extremo pasado del relato de los "vencedores" y el más actual del de los "vencidos". Calificarlos de oficial y contrahegemónico sería una forma de reproducir lo que pretendemos criticar, pero lo cierto es que tiene asidero, y una de las expresiones es que la categoría extinción (como inicio conceptual de una evolución que parece culminar en la de genocidio, en alguna de sus acepciones) todavía permea las percepciones académica, escolar y social sobre el devenir indígena fueguino.

En este trabajo detallamos las aproximaciones historiográficas argentinas y chilenas sobre la Tierra del Fuego, con foco en la consideración de las comunidades indígenas, desde y a través de la siguiente tesis: la marginalidad espacial y el tipo de colonización de Patagonia Austral posicionaron a la Historiografía en un plano secundario respecto de otras disciplinas como la Antropología o la Arqueología; a su vez, la Isla Grande quedó relegada en los abordajes disciplinares incluso cuando éstos aludieron a "la Patagonia" como un bloque. Por último, marcamos cómo (en función del sujeto de estudio) no siempre son discernibles los límites disciplinares (externo-sincrónico), lo mismo que aquellos sobre qué considerar historiográfico (interno-diacrónico), por lo que ceñirnos a la faceta profesional en este caso acotaría en demasía el universo de análisis.

\section{La historiografía en segundo plano: fundamentación contextual}

Patagonia Austral no estuvo sujeta a la administración colonial efectiva hispana y las experiencias de asentamiento fueron breves y fracasaron. Esto no invalidó dos cuestiones fundamentales: por un lado, la región fue un engranaje en la sinergia descubrimientos-modernidad-capitalismo que, con 1492 como emblema, signó la historia de un continente excusándose en un desarrollo que no fue más que el producto de la ecuación capital-recursos naturales; por el otro, los rasgos de colonialidad metropolitana que debiera haber soportado la región entre su visualización y su colonización efectiva, se produjeron a partir de la colonialidad republicana-latifundista de fines del siglo XIX.

El primer aspecto, basado en la razón instrumental que ejerce el capital sobre una naturaleza como entidad no social, apropiada y mercantilizada, socavando incluso sus propias bases de sustentación, comenzó simbólicamente con la primera navegación europea en 1520. Hasta el inicio de la ocupación permanente, en la segunda mitad del siglo XIX, y en conjunción con el hallazgo de las islas Malvinas (1592) y del cabo de Hornos (1616), la región fue escenario de tensiones geopolíticas entre las potencias europeas, pero especialmente de explotación mediante la caza de ballenas, pingüinos, focas y lobos y elefantes marinos. Con la incorporación de Norteamérica como potencia extractivista y de la exploración del canal Beagle (hacia 1830), este saqueo se agudizó, dejando algunas especies al borde de la extinción ${ }^{3}$. Este tránsito impactó principalmente en los pueblos canoeros, a través de matanzas, secuestros, transmisión de enfermedades y disminución de recursos nutricionales: si bien se considera el período entre 1520 y 1850 como de "contacto indirecto", yámanas y

Pueden consultarse al respecto varios trabajos recientes de Marcelo Mayorga (2016, 2018). 
kawésqars padecieron una violencia explícita aunque esporádica y alteraciones sanitarias con consecuencias significativas (Harambour y Barrena 2019).

En cuanto al segundo aspecto, la ocupación permanente de los territorios y maritorios australes sólo se produjo cuando los Estados Nacionales argentino y chileno, en proceso de consolidación, efectivizaron una "doble colonialidad" (Casali 2017). Se dio una situación con rasgos característicos de una etapa colonial dependiente de una metrópoli europea y de una etapa nacional en simultáneo: combinación de agentes extranjeros, capitalistas y religiosos desde entidades supranacionales, con fuerzas estatales (Harambour 2019); de dispositivos de poder disciplinarios y soberanos, violentos y subalternizantes. Las poblaciones de Patagonia Austral tenían formas primigenias, al tiempo que la génesis capitalista fue mediante la versión más financiera, tecnologizada y globalizada posible, con mecanismos y herramientas acumulados en dos revoluciones industriales. Las actividades económicas se desarrollaron en formato de enclave: con una primera etapa basada en el intercambio con los aonikenk, y una poco fructífera de actividad minera, fue la ganadería ovina la que hizo descollar productivamente a la región. Los empresarios ganaderos generaron, gracias al racismo de Estado que los favoreció, un esquema en el que -imbricada o circularmenteoperaron la máxima acumulación de la tierra y del capital británico periférico, junto al monopolio del transporte, la comercialización y la importación; gloria financiera y solvencia empresarial; códigos expansionistas, diversificación comercial y alta capacidad productiva con inversión en tecnologías de la administración del espacio. Así, antes que los imperios o los estados, fueron las estancias ganaderas, posibilitadas por el capital británico expresado como ovejas, las que desataron la conquista del extremo sur americano (Malvinas, norte del Estrecho de Magallanes, Tierra del Fuego, sucesivamente) (Harambour 2019).

El establecimiento conjunto de las soberanías del Estado y del capital, con vértices político-empresariales en Londres, Buenos Aires, Malvinas y Santiago, se expresó con el protagonismo de las empresas de colonización, especialmente de la Sociedad Explotadora de Tierra del Fuego (SETF) y la Sociedad Anónima Importadora y Exportadora de la Patagonia (SAIEP). La triangulación entre la avanzada capitalista tecnológico-financiera, la cualidad geográfica del espacio y el tipo de sociedades (cazadoras-recolectoras), convirtió la colonización en un "hecho total" (Sahlins 1977) e hizo de la colonialidad un acabamiento y refundación de mundo, propia del capitalismo de asentamiento o las sociedades suplantadoras (Day 2006). Las comunidades no contaron con un proceso transicional que les permitiera elaborar estrategias de resistencia colectivas o que mitigaran la desarticulación potenciada por la violencia, el desplazamiento, la deportación y la crisis demográfica.

Este escenario implicó una dinámica intelectual historiográfica que ubicó a la disciplina en un rol secundario respecto de otras. El contraste material y simbólico entre opresores y oprimidos, y el momento en el que sucedió la colonización, dieron lugar a la posibilidad de acceder a las sociedades en su significación "pura" y suspenderlas en una otredad absoluta, en una estereotipación anacrónica e irredimible. Esta operación se dio fundamentalmente desde 1830 con las exploraciones del HMS Beagle (Fitz Roy, Darwin) y se reforzó con los siguientes viajes, entre los que destaca la expedición científica francesa al Cabo de Hornos (La Romanche, 1882-1883). Los fueguinos no sólo fueron trofeo para exposiciones y zoológicos humanos, sino además objeto de las más variadas y violentas cosificaciones en nombre de la ciencia natural, el progreso y el darwinismo social. Los comienzos académicos (a la luz de 
la transición entre la Antropología Evolucionista y la Etnología), produjeron fueguinos paralizados en una preterización y exotización que con las décadas se afianzó materialmente en forma de rituales, imágenes fotográficas y fílmicas, grabaciones sonoras y aprehensión lingüística. Escenario y registros otorgarían a la Antropología excelencia como intervención intelectual y a la Arqueología la cualidad de ciencia paradigmática, liderando disciplinarmente los debates sobre las sociedades "primitivas" de Patagonia Austral. Las temáticas sobre los indiferenciados "fueguinos" refirieron mayormente a tópicos arqueológicos, o quedaron atravesadas por ellos: poblamiento, movilidad, territorialidad, uso del espacio, subsistencia y aprovisionamiento de recursos; tecnología; distribución, disponibilidad y explotación de materias primas; organización social y estructuración grupal. Esta perspectiva, por cierto, se ha reproducido en las formas conmemorativas del turismo étnico (Arqueros et al. 2015; Harambour 2018).

En el siglo XX adquirieron notoriedad metodológica los enfoques de "larga duración” y predominó la perspectiva de la desintegración. La acepción biologicista, de "rescate cultural de los últimos indígenas puros ante la inminente extinción", potenció el análisis desde el tamiz de la ruptura y de la desarticulación, cualidades inobjetables, pero que estimulan el sentido de la irreversibilidad progresista. Se negó la resistencia, y la intelectualidad abonó a la invisibilización de las trayectorias indígenas. Se anuló la alternativa de discernir los intersticios en los cuales subrepticia o contundentemente se manifestó la creatividad y perspicacia indígena, y asir las acciones y devenires que sostuvieron su sobrevivencia; en suma, el pensar historicidades indígenas como parte de un proceso que persistió a pesar de la dominación.

\section{Recorrido historiográfico sobre Tierra del Fuego}

En el siglo XX la mayor parte de la historiografía se apropió del paradigma de la extinción en su aproximación a las comunidades fueguinas, con una potente postura laudatoria de la colonización y "los pioneros". Incorporando lo "indígena" como parte inevitablemente marginal de los relatos, la historia se presentó celebrando la consolidación político-jurisdiccional de los Estados, el poblamiento blanco y el rol de las instituciones civilizatorias (penal, misión, ejército, escuelas, administración) $)^{4}$. Además, por lo expuesto en el apartado anterior, la renovación y consolidación profesional de la historiografía en las transiciones a la democracia (desde 1983 en Argentina y desde 1990 en Chile) no reflejaría para Tierra del Fuego la variedad de debates ocurridos para otras regiones. Para Pampa y Norpatagonia, como para Araucanía, por ejemplo, los núcleos problemáticos que signaron las discusiones dieron cuenta no sólo de los cambios de paradigma para aprehender las comunidades indígenas como objeto de análisis, sino también de la expresión heurística de procesos de colonización disímiles a los australes. Con los años 80 como germen de las visiones consolidadas desde los años 90 , y con espacios de publicación, redes y encuentros específicos, se revisitaron el concepto de frontera y las relaciones fronterizas, dando lugar a variados y numerosos tópicos que "anclaban en" o "interpelaban a" la

\footnotetext{
$4 \quad$ En este sentido, es significativa la continuidad hasta nuestros días de las perspectivas salesiana y latifundista en la vasta obra de Martinic (ver Nota 10), quien además ofició como autoridad política en Magallanes y ha definido los símbolos, efemérides y políticas de patrimonialización en esa región chilena.
} 
agencia indígena, a sus dinámicas y a las estrategias para enfrentar la dominación: economía y control territorial; organización sociopolítica, parentesco, liderazgos y jerarquización social; sobrevivencia invisibilizada luego de las campañas militares; representaciones en torno a las comunidades y discursos hegemónicos sobre políticas indigenistas 5 .

El sendero historiográfico tiene una génesis en la vertiente de la narrativa colonizadora (desde 1880 hasta los años 70). Por un lado, los relatos propios de un conocimiento científico en pos de "la definición de un territorio de dominación (relevamiento, exploración, cartografía, clasificación de los elementos naturales, conocimiento de las características de la población), de la construcción de un modelo de Estado liberal ilustrado que, bajo su proyecto nacional, buscó homogeneizar la sociedad y eliminar todo componente social y político que lo pusiera en cuestión" (Zusman 2005). En 1895, a pedido del gobernador Pedro Godoy ("progresista" a cargo de la exposición en el zoológico humano en Buenos Aires en 1898), Francisco Moreno organizó una expedición fueguina integrada por Nicolás Alboff ${ }^{6}$, Fernando de Lahille ${ }^{7}$, Emilio Beaufils (embalsamador del Museo de La Plata, adonde llevó el esqueleto de una mujer selk'nam víctima del famoso remate de indios de 1895) y Carlos de Lahitte ${ }^{8}$. Se destaca la expedición científico-militar dirigida por Ramón Lista (1886), en la que participara Polidoro Segers (1891) como médico, célebre por contar en su tripulación con el misionero salesiano Giuseppe "José" Fagnano (arquitecto del diseño misional salesiano), y también por ocasionar la primera matanza documentada de la isla Grande. En ella murieron 28 selk'nam, y ha dado origen al "Día del Indígena Fueguino", hoy "Día del Genocidio Selk’nam". Otros productos de la legitimación científica de esta avanzada estatal fueron las obras de Bove (1883), Lehmann Nitsche (1904,1915), Dabbene (1904) y Gallardo (1910), que viajaron juntos en 1902 por encargo del Ministerio del Interior, Eduardo Holmberg -hijo del famoso naturalista-, que escribió sobre su viaje para los Anales del Ministerio de Agricultura (1906). A su vez, Roberto Payró representa emblemáticamente la versión periodística del proyecto de invención de los Estado-Nación, con la particularidad de permitirse lecturas críticas de aquella oligarquía abandónica, en un contexto reformista más lícito para los debates en torno a la figura del Estado luego de la revolución de 1890, de la "crisis moral" dada a partir de la no consolidación de las prácticas liberales (Navarro 2009). El escritor recorrió la región austral y publicó sus minuciosas impresiones en el diario La Nación, luego recopiladas en el libro La Australia Argentina (Payró 1898), de gran valor etnográfico.

Por otra parte, se encuentran los relatos de quienes directamente ejecutaron la colonización. Una primera etapa estuvo protagonizada por el reverendo anglicano Thomas Bridges, primer poblador "blanco" de la isla, "fundador" de Ushuaia y casi gobernador si hubiera accedido al ofrecimiento del general Roca. Además de sus escritos para la South American Missionary Society, Bridges generó "datos sobre la Tierra del Fuego y sus habitantes" publicados en la Revista del Museo de La Plata o el Boletín del Instituto Geográfico Argentino (1886, 1891, 1893), todo lo cual fue

\footnotetext{
Ver detalles sobre tópicos y autores en Salomón y Casali 2015; para el caso de Araucanía, ver los recientes aportes de la Comunidad de Historia Mapuche.

1896, "La naturaleza en la Tierra del Fuego", entre otros escritos

1897, "Fines de verano en la Tierra del Fuego"; 1926, "Matériaux pour servir à l'histoire des oonas indigènes de la Terre de Feu".

1901, "Los Onas"; 1904, "Leyendas Fueguinas"
} 
luego convertido en libro (Bridges 1998). Este primer momento contó también con los proyectos mercantiles de Julio Popper, ingeniero rumano que descubriera oro en la zona de San Sebastián para dónde propuso la formación de un pueblo marítimo llamado Atlanta. Tal es el nombre del libro (Popper 2003) que recupera aquella planificación, su conferencia en el Instituto Geográfico Argentino (1887) y algunos artículos publicados en diarios. Es sabido que Popper se destaca en la historia por los crímenes contra indígenas y el desafío a la autoridad estatal chilena y argentina, manifestado en la acuñación de moneda, la impresión de estampillas postales y el enfrentamiento con el gobernador Cornero, que resultó suspendido.

Una segunda etapa correspondió a los misioneros salesianos que llegaron a Dawson en 1889 (misión de San Rafael) y al noreste de Tierra del Fuego en 1893 (misión La Candelaria). En la primera línea de los dispositivos de poder, los salesianos fueron los principales productores del material sobre la comunidad selk'nam (censos, diarios, actas de nacimiento y defunción, etc.), recuperado analíticamente a comienzos del siglo XXI; pero además de aquel secundario, entre los que se destacan los testimonios de Borgatello (1924), Beauvoir (1915), Del Valle Carbajal (1900), Coiazzi (1911), Migone (1935), Massa (1945) y De Agostini (1956). La egregia obra de Martín Gusinde (cuatro viajes al archipiélago fueguino entre 1918 y 1924, cuyo producto principal son los tomos editados en los años 80; 1982-1991), podría ubicarse en este acápite en función de su cualidad de religioso, pero su minuciosa lectura sobre las comunidades fueguinas cuadra más en la rotulación de etnográfica, además de que -aunque lógico representante del Occidente darwinista y colonizador- cabe una diferencia con los taxativos artífices de la colonialidad, anglicanos y salesianos.

Pretendemos remarcar una tercera etapa dentro de este grupo, en la que escriben los "descendientes", en la que los empresarios ganaderos legitiman su existencia en un escenario de indígenas semi "extintos" y de producción ovina en crisis (apertura del canal de Panamá, disminución de la demanda y precio del producto, huelgas de los peones rurales, sequías, reimplantación de los impuestos aduaneros, etc.). El último confín de la tierra (1948), se convirtió en una de las más emblemáticas obras etnohistóricas: escrita por Lucas Bridges, uno de los hijos de aquel "primer blanco" en la isla, prácticamente criado junto a yaganes y selk'nam, formó parte de sus ceremonias y mantuvo un vínculo en sus estancias que no excluía su aprovechamiento como mano de obra. Lo cierto es que, del lado de los empresarios ganaderos que persiguieron indígenas, se consolidó un autorretrato de exculpación y justificación a la vez que natural expresión de su poder y de su autopercibida y postulada cualidad de voz oficial. Fue el hijo de Mauricio Braun y Josefina Menéndez, Armando, quien oficiando como historiador efectuó esta labor con más de doscientos trabajos desde la perspectiva colonizadora sobre el acontecer austral (sólo como ejemplo, 1939). Pero uno de los capítulos más destacables en este sentido es el de la publicación que financiara la SETF-SAIEP. Entre 1929 y 1967 se publicó la revista Argentina Austral, lobby estanciero en Buenos Aires que la autora Martha Ruffini (2017) posiciona como periodismo "educativo", "prensa de frontera", "impulsor de la civilización", "mediador cultural" en Territorios Nacionales con "carencia de representantes ante el Congreso de la Nación y la ciudadanía política restringida en su dimensión electoral-nacional", donde era preciso difundir principios de nacionalidad y potenciar identidades. En este contexto se alzó la voz disidente del periodista español José María Borrero, quien en La Patagonia trágica (1928) denunció a los estancieros por la doble masacre, la de los pueblos originarios y la de peones rurales, como causa 
y efecto del monopolio económico-social y su correlato en los sentidos comunes performativos de la Nación.

Lógicamente, la historiografía de Tierra del Fuego fue cruzada en los años 70 por los tintes tradicionales (Pesagno Espora 1971; De Imaz 1972; Lewin 1974), los eclesiásticos (Entraigas 1945; Paesa 1976) y por quienes, desde esta perspectiva y pertenencia, sentaron las bases de un análisis documental extenso y meticuloso para las investigaciones venideras: Arnoldo Canclini como historiador y pastor bautista, y Juan Belza como historiador y salesiano. Canclini escribió hasta el final de su vida (en 2014) y dejó numerosas obras sobre la isla, Ushuaia y sus sucesivos habitantes?, mientras que Belza no sólo legó sus tres tomos sobre "la isla del fuego" (1974-1977, Encuentros, Colonización y Población), sino que además fundó el Instituto de Investigación de Tierra del Fuego y su medio, la revista KaruKinka, con decenas de monografías en treinta cuadernillos de numerosos y diversos tipos de autores (Raúl Entraigas, Hebe Viglione Arrastía, Armando Vittani). La década de 1970 marcó, además, el comienzo de la prolífica e influyente trayectoria del abogado Mateo Martinic, fundador y director por décadas del Instituto de la Patagonia y de la revista Magallania, con financiamiento permanente a pesar de los severos recortes a la investigación efectuados por la dictadura chilena ${ }^{10}$.

La impronta de la perspectiva de los procesos de consolidación de los EstadoNación continuó en la década de 1980. Las tendencias de la historiografía profesional arribaron modestamente al estudio de la Tierra del Fuego que quedaba relegada en los abordajes sobre la "frontera sur" que podrían haberla incorporado. En los años 80 se desarrollaron trabajos sobre el poblamiento blanco, la propiedad de la tierra, el papel del penal de Ushuaia y de los misioneros, con una escritura (signada por problemáticas latentes como la cuestión limítrofe o Malvinas) todavía a cargo de abogados, militares, politólogos, religiosos o aficionados (Kuzmanich 1980; Fogg, 1983; Szanto 1982; García Basalo 1988), o de quienes ostentaban pertenencia o cercanía a los salesianos (Bruno 1981; Aliaga 1984). El ítem indígena -aunque consideradoingresó a la arena historiográfica profesional como objeto primario y específico sólo hacia fines de la década con los trabajos de María Teresa Luiz (1988a, 1988b, 1988c, 1990a, 1990b, 1990c, 1990d, 1991), y se potenció en los años 90 con la incorporación de Mónika Schillat (Luiz y Schillat 1997, 2001) y con la producción de María Andrea Nicoletti (1997, 2006, 2009), que no sólo abrió caminos, sino que además aún continua. La profesionalización no impidió la continuidad hasta nuestros días de los abordajes de corte amateur (Perich 1995), con grado disímil de rigurosidad y de condicionamiento de lo pintoresco del fin del mundo y sus culturas extintas.

Una mención especial merece la obra de Nelly Penazzo, médica que en 1967 se mudó a Río Grande, donde eligió atender a miembros de la etnia selk'nam como Angela Loij, Luis Garibaldi, Federico Echeuleilene-, a quienes interpeló como informantes. Wot'n documentos del genocidio ona fue publicado el mismo año de fallecimiento de la autora (Penazzo y Tercero 1996), y sus 503 páginas fueron divididas en tres tomos por la pequeña editorial que lo produjo. Con una narrativa de montaje, la obra es un recurso ineludible para cualquier análisis sobre la vida y so-

9 "Indios fueguinos, vida, costumbres es historia"; "El Fueguino, la cautivante historia de Jemmy Button", "Indios, policías y agitadores: documentos policiales fueguinos"; etc. http:/www.memoriachilena.gob.cl/602/w3article-3605.html\#documentos.

10 Citamos sólo un ejemplo (Martinic 1982) debido al tamaño de su obra, que puede consultarse en los sitios de la revista Magallania y de Memoria Chilena. 
brevida selk'nam. Por un lado, no sólo compendia información de fuentes primarias (documentación oficial, diarios misionales), relatos de viajeros, escritos etnohistóricos y fuentes secundarias tradicionales, sino que es en sí mismo un rico testimonio etnográfico. Por otro lado, combina minuciosidad historiográfica y antropológica, soterrando una autoría aficionada que visibiliza a la comunidad selk'nam y ausculta el devenir etnocida. En un formato más tradicional, de crónica periodística y rescate de documentos primarios, Carlos Vega (1995, 1996a, 1996b, 2012; Vega y Grendi 2002), desde Punta Arenas, lideró en su propia obra, y a través de la editorial Atelí, una reemergencia del estudio sobre voces indígenas (haush, selknam, kawésqar) y obreras de comienzos del siglo XX, irrumpiendo en un medio local dominado por el historiador-político Martinic.

Lo expuesto explica en parte la invisibilización de las comunidades indígenas en los relatos "académicos", operación no exclusiva de la historiografía, pero en la cual la consideración estuvo inherentemente focalizada en una sociedad blanca presentada como homogénea. Esta particular construcción facto-intelectual coaguló en una historiografía y una patrimonialización donde las comunidades no lograron escapar de las trampas materiales y discursivas para poder conciliar los tiempos como parte de un todo diverso pero unívoco: pasado y presente en una misma narrativa intelectual con eje en la sobrevivencia. En el nuevo siglo se consolidó la reemergencia indígena, que venía asomando desde el retorno de la democracia, como manifestación de identidades siempre latentes: un reconocimiento a partir del cual los propios sujetos indígenas se configuraron "como actores políticos involucrados en la implementación de agendas públicas, así como en los modos de presentarse a sí mismos y conceptualizar sus identidades, prácticas culturales, memorias, lenguas, derechos y formas de organización" (Lazzari y Quarleri 2015).

En paralelo - o dialécticamente-, los artículos y tesis doctorales sobre Patagonia Austral permitieron profundizar en una problematización analítica específica y en perspectivas teóricas diferenciadas. Autores como Paoloni (2004), Luiz (2006), Baez (2009), Casali (2013a), Nacach (2011), Bascopé (2012), Odone (2013) y Harambour y Barrena (2019), han contribuido a poner en agenda la singularidad de lo "indígena", sus agencias y dinámicas. Por un lado, resignificando la ocupación y fundamentando los procesos como colonialidades con múltiples dispositivos de poder y continuos formatos de sujeción y subalternización. La categoría genocidio se sumó luego como vertebradora de estas nuevas explicaciones y formas de comprender, de dimensionar responsabilidades estatales y privadas; de reconstruir una memoria social en pos de la verdad anulada mediante posverdades coloniales. Por otro lado, se dio una oportunidad a la disciplina para contribuir a la reconstrucción de las trayectorias comunitarias. Con nuevas perspectivas teóricas, periodizaciones y escalas de análisis, se propusieron esquemas de sobrevivencia, por ejemplo, a partir del estudio de las modificaciones que los selk'nam desarrollaron en función de su racionamiento, su situación residencial y los modos relacionales. Se superaron las visiones iniciales que indicaban evasión como mecanismo de defensa de cariz tradicional y la labor en las estancias como expresión de la aculturación, y se trascendieron posturas dicotómicas: los selk'nam habrían combinado la evasión y el contacto, el conflicto y los modos inocuos, los modos tradicionales y los capitalistas, con un correlato en vinculaciones multidireccionales y flexibles étnicamente ${ }^{11}$. En definitiva, las altera-

11 Ver detalles en Casali 2013a, 2013b, 2013c; Casali y Manzi 2017. 
ciones intracomunitarias han sido recuperadas en términos de construcciones y no sólo de desintegraciones como parte de un proceso continuo de mecanismos y herramientas que habilitan anular la idea de irreversibilidad de la colonización, y pautar una continuidad étnica con quienes hoy se autoperciben como indígenas.

\section{A modo de cierre}

Una historiografía marcada por la celebración progresista de la conquista de la Tierra del Fuego; una conquista ovina extranjera, supuestamente blanca y presuntamente nacional (argentina y chilena) caracterizó la narrativa desde fines del siglo XX y casi hasta nuestros días. Siguiendo la distinción moderna entre Historia y Prehistoria, la primera se inauguró destruyendo a la segunda y relegándola a la Arqueología y a la Antropología Física o religiosa. Un cuadro intelectual en el que no sólo la pluma científico-estatalizante obtuvo una relevancia excesiva, sino principalmente la de los propios opresores y la de los aficionados, con su inclaudicable estandarte de exotismo socioespacial.

Recién desde la década de 1990 la renovación historiográfica de las zonas centrales de Chile y Argentina comenzó a recoger, de forma experimental, a veces incoherente, y siempre insuficiente, los trazos de la sobrevida indígena y de su plana existencia, truncada por el capitalismo racial. En las dos últimas décadas, las relecturas disciplinares críticas, las voces de las comunidades en reorganización y la crítica ciudadana han vuelto al tópico de la colonización y la agencia indígena y popular, y logrado transformar la patrimonialización colonialista de la historicidad de la Isla Grande de Tierra del Fuego. Constituye un desafío resignificar la Patagonia Austral en su estatus regional y mundial: ni una extraña marginalidad que habilita esencialismos, ni excepcionalismo capitalista de la acumulación originaria, extractivista y genocida. También está en marcha una cierta oficialización de estas nuevas miradas, pasándolas a través de la academia, no en un sentido de homogeneización y sujeción nacionalizante, sino como valorización y construcción de nuevas verdades sobre las historias de los pueblos.

\section{Referencias}

Aliaga, Fernando. 1984. La Misión en la Isla Dawson (1889-1911). Santiago: Universidad Católica de Chile.

Arqueros, Gonzalo, Andrés Azúa, Jorge Hidalgo, Andrés Menard, Héctor Morales, Loreto Quiroz, Giannina Radjl, Mauricio Uribe y Francisca Urrutia. 2015. «Patrimonio como extinción: Magallanes en el imaginario chileno». Sophia Austral 16: 15-40

Báez Allende, Christian. 2009. Más allá de las imágenes. Fotografias de fueguinos y patagones en contextos de exhibición (1878-1898). Tesis de Doctorado en Historia. Pontificia Universidad Católica de Chile.

Bascopé, Joaquín. 2012. La colonisation de la Patagonie australe et la Terre de Feu Sources pour une histoire internationale 1877-1922. Tesis de Doctorado en Sociología. París: l'École des Hautes Etudes en Sciences Sociales.

Beauvoir, José Maria. 1915. Los shelknam, indigenas de la Tierra del Fuego: sus tradiciones, costumbres y lengua por los misioneros salesianos. Buenos Aires: Talleres Gráficos de la Compañía General de Fósforos. 
Belza, Juan. 1974, 1975, 1977. En la isla del fuego. 3 vols. Buenos Aires: Instituto de Investigaciones Tierra del Fuego.

Borgatello, Maggiorino. 1924. Nella Terra del Fuoco. Memorie de un Missionero Salesiano. Torino: Societa Editrice Internazionale.

Borrero, José María. 1999 (1928). La Patagonia trágica. Buenos Aires: Peña Lillo.

Bove, Giacomo. 2005 (1883). Expedición a la Patagonia. Un viaje a las tierras y mares australes (1881-1882). Buenos Aires: Continente.

Braun Menéndez, A. 1939. Pequeña historia fueguina. Buenos Aires: Emecé.

Bridges, Lucas. 1948. Uttermost part of the earth. Londres: Hodder \& Stoughton

Bridges, Thomas. 1998. Los indios del último confin. Sus escritos para la South American Missionary Society. Ushuaia: Zagier \& Urruty.

Bruno, Cayetano. 1981. Los salesianos y las Hijas de María Auxiliadora en la Argentina. 3 Tomos. Buenos Aires: Instituto Salesiano de Artes Gráficas.

Casali, Romina. 2013a. Conquistando el fin del mundo. La misión La Candelaria y la salud de la población selk’nam, Tierra del Fuego 1895-1931. Rosario: Prohistoria.

- 2013b. «Movilidad y uso del espacio: análisis demográfico de la trayectoria selk’nam ante la colonización. Tierra del Fuego, Argentina, 1890-1930». Anuario del Instituto de Historia Argentina 13: 112-126.

- 2013c. «Relaciones interétnicas en Tierra del Fuego: el rol de la misión salesiana La Candelaria (1895-1912) en la resistencia selk'nam». Revista de Estudios Marítimos y Sociales 5/6: 105-117.

- 2017. «De la extinción al genocidio selk’nam: sobre Historia e historias para una expiación intelectual. Tierra del Fuego, Argentina». A Contracorriente: una revista de estudios latinoamericanos 15 (1): 60-78.

Casali, Romina y Liliana Manzi. 2017. «Etnicidades capitalistas: el rol de la Estancia San Pablo en el entramado de resistencia selk'nam. Tierra del Fuego, 1904-1930». Magallania 45 (2): 109-133. http://dx.doi.org/10.4067/S0718-22442017000200109

Coiazzi, Antonio. 1911. Gli Indii dell'Arcipelago Fueghino. Torino: Buona Stampa.

Dabbene, Roberto. 1904. «Viaje a TDF y a la isla de los estados». Boletín del Instituto Geográfico Argentino XXI: 3-78.

Day, David. 2006. Conquista. Una nueva historia del mundo moderno. Barcelona: Editorial Crítica.

De Agostini, Alberto. 1956. 30 años en Tierra del Fuego. Buenos Aires: Ediciones Peuser.

De Imaz, José Luis. 1972. Los hombres del confin del mundo. Buenos Aires: Editorial Universitaria de Buenos Aires.

Del Valle Carbajal, Lino. 1900. Le Missioni salesiane nella Patagonia e Regioni Magallaniche. Studio Storico-Statistico. Torino: Benigno Canavese.

Entraigas, Raúl. 1945. Monseñor Fagnano, el hombre, el misionero, el pionner. Buenos Aires: Editorial S.E.I.

Fogg, Guillermo J. 1983. Soberanía argentina en el área austral. Buenos Aires: Editorial Pleamar.

Gallardo, Carlos R. 1910. Los onas. Tierra del Fuego. Buenos Aires: Cabaut y Cía. Editores. García Basalo, Juan C. 1988. La colonización penal de Tierra del Fuego. Buenos Aires: Marymar.

Gusinde, Martín. 1982-1991. Los Indios de Tierra del Fuego. 4 tomos en 9 volúmenes. Buenos Aires: Centro Argentino de Etnología Americana, CONICET.

Harambour, Alberto R. 2018. «Los prohombres y los extintos. Patrimonio, identidad e historiografía regional en Magallanes». Cuadernos de Historia 48: 57-88. 
- 2019. Soberanías fronterizas: estados y capital en la colonización de Patagonia (Argentina y Chile, 1830-1922). Valdivia: Universidad Austral de Chile.

Harambour, Alberto y José Barrena. 2019. «Barbarie o justicia en la Patagonia Occidental: las violencias coloniales en el ocaso del pueblo kawésqar, finales del siglo XIX e inicios del siglo XX». Historia Crítica 71: 25-48.

Holmberg, Eduardo. 1906. Viaje al interior de Tierra del Fuego. Buenos Aires: Talleres de Publicaciones de la Oficina Meteorológica Argentina.

Kuzmanich, Simón. 1980. Cuatro pueblos y un destino. Santiago: Editorial Salesiana.

Lazzari, Axel y Lía Quarleri. 2015. «Introducción. Pueblos indígenas y Antropología en Argentina. Balances y perspectivas (1984 al presente)». Papeles de Trabajo 9 (16): 14-21.

Lehmann-Nitsche, Robert. 1904. «Braquifalangia de la mano derecha con sindactilia parcial del índice y dedo medio observada en una india ona de la Tierra del Fuego». Revista Museo de la Plata II: 20-209.

-. 1915. «Études anthropologiques sur les indiens ona (groupe tshon) de la Terre de Feu». Revista Museo de la Plata 23: 174-184.

Lewin, Boleslao. 1974. Quien fue el conquistador patagónico Julio Popper. Buenos Aires: Plus Ultra.

Lista, Ramón. 1886. Viaje al país de los Onas. Buenos Aires: Establecimiento Tipográfico de Alberto Núñez.

Luiz, María Teresa. 1988a. «Un perfil de las sociedades aborígenes de Tierra del Fuego». Revista Proyecciones 1 (separata).

-. 1988b. «Cronología de Tierra del Fuego. Desde el poblamiento inicial hasta la primera mitad del siglo XIX». Revista Proyecciones 2: 34-38.

- 1988c. «Cronología de Tierra del Fuego. Inicio del poblamiento blanco y de la colonización». Revista Proyecciones 3: 24-28.

- 1990a. "Cronología de Tierra del Fuego. De 1900 a nuestros días". Revista Patagónica 44: 47-51.

-. 199b. “Cronología de Tierra del Fuego. De 1900 a nuestros días". Revista Patagónica 45: 45-47.

-. 1990c. “Cronología de Tierra del Fuego. De 1900 a nuestros días". Revista Patagónica 46: $45-47$.

- 1990d. "Cronología de Tierra del Fuego. De 1900 a nuestros días". Revista Patagónica 47: 27-30.

-. 1991. “Cronología de Tierra del Fuego. De 1900 a nuestros días”. Revista Patagónica 48: 6-8.

- 2006. Relaciones fronterizas en Patagonia. La convivencia hispano indígena a fines del periodo colonial. Ushuaia: Asociación Hanis.

Luiz, María Teresa y Mónika Schillat. 1997. La frontera austral. Tierra del Fuego, 15201920. Cádiz: Servicio de Publicaciones de la Universidad de Cádiz.

- 2001. «De la virtualidad de las fronteras políticas a la realidad de la frontera en el imaginario. Patagonia meridional y Tierra del Fuego, siglos XVI-XX», en Cruzando la cordillera...la frontera argentino-chilena como espacio social, Susana Bandieri, coord., pp. 167-190. Neuquén: Centro de Estudios de Historia Regional, Facultad de Humanidades, Universidad Nacional del Comahue.

Martinic, Mateo. 1982. La tierra de los fuegos. Magallanes: Municipalidad de Porvenir.

Massa, Lorenzo. 1945. Monografía de Magallanes: sesenta años de acción salesiana en el Sur, 1886-1946. Punta Arenas: Instituto Don Bosco. 
Mayorga Zúñiga, Marcelo. 2016. «Antecedentes históricos referidos a la caza de lobos marinos y su interacción con el medio geográfico y humano en el extremo austral americano: el caso del lobero escocés William Low». Magallania 44 (2): 37-64. http://dx.doi.org/10.4067/S0718-22442016000200002

- 2018. «Loberos yankees: encuentros/desencuentros en torno a la Tierra del Fuego y Patagonia». Revista Estudios Hemisféricos y Polares 9 (4): 28-44.

Migone, Mario. 1935. Un héroe de la Patagonia. Buenos Aires: Colegio Pío IX.

Nacach, Gabriela. 2011. La deriva de la alteridad entre las lógicas de raza y clase en la Patagonia. El censo de 1895 en el contexto del proceso de incorporación diferenciada de los indígenas. Tesis de Doctorado. Facultad de Filosofía y Letras. Universidad de Buenos Aires.

Navarro Floria, Pedro. 2009. «La mirada del reformismo liberal sobre los Territorios del Sur argentino, 1898-1916». Quinto Sol 13: 73-103.

Nicoletti, María Andrea. 1997. «La vida cotidiana de los fueguinos». Historia XVII (66): 120-130.

- 2006. «Los misioneros salesianos y la polémica sobre la extinción de los Selk’nam». Anthropologica XXIV (24): 153-177.

-. 2009. «Salesianos e Hijas de María Auxiliadora en el Fin del Mundo: educar, "civilizar" y evangelizar en las reducciones de Tierra del Fuego», en Operosità missionaria e immaginario patagônico, Nicola Bottiglieri, ed., pp. 63-91.Cassino: Edizioni Università di Cassino.

Odone Correa, María Carolina. 2013. La experiencia histórica de los que allí vivieron (Isla Dawson, Tierra del Fuego, 1889-1911). Tesis de Doctorado, Instituto de Historia. Santiago: Pontificia Universidad Católica de Chile.

Paesa, Pascual R. 1976. «Los indios de la Patagonia y la acción salesiana». Suplemento Boletín Salesiano, 2: 4-36.

Paoloni, Rosana. 2004. «Los Selk'nam. Vida, mitos, ritos y muerte en un pueblo del "fin del mundo"». Anuario del Instituto de Estudios Histórico Sociales 19: 497-516.

Payró, Roberto. 1898. La Australia argentina. Excursión periodística a las costas patagónicas, Tierra del Fuego e Isla de los Estados. Buenos Aires: Imprenta de la Nación.

Penazzo, Nelly Iris y Guillermo Tercero Penazzo. 1996. Wot'n documentos del genocidio ona. Buenos Aires: Ediciones Arlequín de San Telmo.

Perich Slater, José. 1995. Extinción indígena en la Patagonia. Punta Arenas: Horizonte.

Pesagno Espora, Mario A. 1971. Los fueguinos. Buenos Aires: Departamento de Estudios Históricos Navales, Secretaria General Naval.

Popper, Julio. 2003. Atlanta. Proyecto para la fundación de un pueblo marítimo en Tierra del Fuego y otros escritos. Buenos Aires: Editorial Universitaria de Buenos Aires.

Ruffini, Martha 2017. La Patagonia mirada desde arriba. El grupo Braun-Menéndez Behety y la Revista Argentina Austral, 1929-1967. Rosario: Prohistoria.

Sahlins, Marshall. 1977. Islas de la Historia. La muerte del capitán Cook. Metáfora, antropología e historia. Barcelona: Gedisa Editorial.

Salomón Tarquini, Claudia y Romina Casali. 2015. «Los pueblos indígenas de Pampa y Patagonia, siglos XVIII-XX: un breve estado de las investigaciones». Papeles de Trabajo 16: 22-55.

Segers, Polidoro. 1891. «Hábitos y costumbres de los indios onas». Boletín del Instituto Geográfico Argentino XII: 56-82.

Szanto, Ernesto. 1982. Los salesianos en el país de los Césares. Buenos Aires: Marymar. 
Vega Delgado, Carlos. 1995. Cuando el cielo se oscurece (Samán arkachoé): historia de vida, testimonio alacalufe de Alberto Achacaz Walakia. Punta Arenas: Imprenta y Editorial Atelí.

- 1996a. La masacre de la Federación Obrera de Magallanes. El movimiento obrero patagónico-fueguino hasta 1920. Punta Arenas: Imprenta y Editorial Atelí.

-. 1996b. Sombras de fuego-Patagonia. Punta Arenas: Imprenta Atelí.

- 2012. Los Haush. Punta Arenas: Imprenta y Editorial Atelí.

Vega Delgado, Carlos y Paola Grendi. 2002. Los vejámenes a indígenas de Tierra del Fuego. Tomo III. Punta Arenas: Corporación Nacional Indígena XII Región.

Zusman, Perla B. 2005. «Pedro Navarro Floria (comp.). Patagonia. Ciencia y conquista. La mirada de la primera comunidad científica argentina». Biblio $3 W$. Revista Bibliográfica de Geografia y Ciencias Sociales X (577). https://www.raco.cat/index.php/Biblio3w/article/ view/70345. 